\title{
Disability, Perceived Discrimination and Political Participation
}

\section{Mattila, Vesa Mikko}

2017

Mattila , V M \& Papageorgiou , A 2017 , ' Disability, Perceived Discrimination and Political

Participation ' , International Political Science Review , vol. 38 , no. 5 , pp. 505-519 . https://doi.org/10.1177/0192512

http://hdl.handle.net/10138/229738

https://doi.org/10.1177/0192512116655813

submittedVersion

Downloaded from Helda, University of Helsinki institutional repository.

This is an electronic reprint of the original article.

This reprint may differ from the original in pagination and typographic detail.

Please cite the original version. 


\title{
Disability, Perceived Discrimination and Political Participation
}

\section{Mikko Mattila* \& Achillefs Papageorgiou**}

*Department of Political and Economic Studies, University of Helsinki; Corresponding author: Email: mikko.mattila@helsinki.fi

** Department of Political and Economic Studies, University of Helsinki and Department of Politics and Public Administration, University of Limerick

\begin{abstract}
Disability affects the lives of hundreds of millions across the world. People with disabilities often experience discrimination and unequal treatment. Sometimes the mere categorization of people into groups, i.e., 'healthy' vs. 'disabled', is enough to trigger discriminatory behaviour against people with disabilities. Previous studies show that in general disabilities depress political participation. However, the effect of disability-based discrimination on participation has received little scholarly attention. We study how perceptions of discrimination affect three forms of political participation: voting, contacting politicians and participating in demonstrations. Results show that disability decreases voting, especially when associated with perceptions of discrimination. The analysis points in the opposite direction when the other two forms of political participation are analysed. People with disabilities are more likely to partake in demonstrations and contact politicians than nondisabled. Thus, disability-based discrimination is not always a hindrance to participation. It sometimes further motivates people with disabilities to participate.
\end{abstract}

Funding acknowledgement: This work was supported by the Academy of Finland (grant number 266844). 


\section{Introduction}

According to the World Health Organization (WHO) (2011), over one billion individuals worldwide, that is around $15 \%$ of the world's population, experience in their everyday lives some type of disability. This figure is likely to rise given the ageing population and the increase in chronic health conditions in the developed countries, on the one hand, and the persistence of war and poor health conditions in many developing countries, on the other. Disability is a complicated concept and therefore a universally acceptable definition is difficult to find (Altman, 2001). Often the term is used to describe people in relation to others according to a lack of ability or a certain characteristic. In a broader sense, disability is always defined in the wider societal context. In other words, disability is a social construction that translates a health condition into a social pathology that may constrain persons from functioning effectively in their society (Gregory, 1996). ${ }^{1}$ As a relational term, disability often triggers discriminatory behaviour against those who fall into the category of 'disabled' (out-group) by 'healthy' others (in-group). Discrimination disempowers and stigmatizes people with disabilities in a multitude of ways and in different areas of the social sphere.

We analyse the effects of perceived disability-based discrimination on political participation. Although there have been studies focusing on the effect that poor health or disabilities have on political participation (e.g., Schur et al., 2005; Mattila et al., 2013; FRA 2014; Grammenos, 2013; Valentine and Vickers, 1996) this study is one of the few that approaches the issue of disabilitybased discrimination in political participation empirically by a) employing survey data from multiple (32) countries; and b) relying on an integrated theoretical framework derived from political and social psychological theories. Furthermore, our results can help us to understand political participation in a wider perspective. Our hypotheses, based on social psychology theories of collective action, can be applied to analyse collective action among members of any disadvantaged group. 
We have two main research questions: How do disabilities and perceived disability-based discrimination affect political participation among people with disabilities? And what forms of political participation are more likely to be affected by perceived discrimination against people with disabilities? These are important questions that have not been studied quantitatively in a comparative setting before. By providing answers to these questions, the present study fills in a lacuna in the scholarly literature related to political participation and collective action.

The manuscript is organized as follows. First, we present the theoretical framework of the current study. The following two sections discuss the concept of discrimination and the effect of disability on collective action. Then we present the hypotheses of our study and the data used in the analysis. The final sections discuss the results and the conclusions one can draw from them.

\section{Theoretical framework}

One way to understand collective action is to see it as a form of activity where individuals attempt to influence the outcome of a public good. According to Wright (2009: 860), a "group member engages in collective action any time she or he acts as a representative of the group and where the action is directed at improving the conditions of the group as a whole". In this sense, practically all political participation can be seen as collective action. The factors affecting why individuals take part in collective action have been analysed at least in the fields of political science, sociology, economics and social psychology. Here we concentrate on individual-level determinants of political participation. In particular, we use elements of political science and social psychology theories to construct our framework to explain participation among people whose lives are affected by some type of disability.

Theoretically, collective action can be studied either from macro- or micro-level perspectives, although sometimes the lines between these two approaches can be blurred. On macro level, 
resource mobilization, social network and political opportunity structure theories have been influential (see, e.g., Della Porta and Diani 2006) and they have also been applied on micro-level studies. From social movement and identity politics perspectives the political mobilization of disability groups, nationally and internationally, have been studied by, for example, Anspach (1979) and Driedger (1989).

However, we choose to approach our research problem of collective action among people with disabilities from an explicitly individual-level perspective. In social psychology two influential theories explaining collective action are the relative deprivation theory (RDT) and the social identity theory (SIT) (van Zomeren and Iyer, 2009). Although distinct approaches, these theories lead to fairly similar overall hypotheses concerning the factors mobilizing people into collective action. According to the relative deprivation theory, it is relative (as opposed to absolute) differences that matter (Smith at al., 2012). A person can feel a personal relative deprivation (wherein the feeling of deprivation is relative to other individuals) or a collective relative deprivation (wherein the feeling of deprivation is relative to an out-group). Since collective action entails a sense of group identification, the prime motivator for collective action is the feeling of collective rather than personal relative deprivation (Kelly and Breinlinger, 1996). Empirical studies have confirmed that personal deprivation is less likely to trigger collective action than collective deprivation (Walker and Mann, 1987).

Group members evaluate their position in relation to others, and if they perceive their position as comparatively disadvantaged they are motivated to take part in political action to improve their situation. However, merely being a member of a disadvantaged group is not enough. Mobilization also requires an emotional component: a feeling of resentment that the group is being treated unfairly. This resentment may grow, e.g., out of experiences of discrimination against one's group. These two components, membership in a disadvantaged group and resentment, together create the 
incentives for collective action. The feeling of anger regarding an existing inequality or the feeling that an inequality is intense and persistent further triggers collective action (Birt and Dion, 1987).

Social identity theory emphasizes identification with one's own group (in-group) and comparisons with other groups (out-groups) which lead to attempts to change the prevailing situation when the status of one's own group is seen unfavourably in comparison (Tajfel and Turner, 1979). Collective action is boosted when the social identity prevails over the personal one and people 'come to perceive themselves more as interchangeable exemplars of a social category than as unique personalities defined by their individual differences from others' (Turner et al., 1987: 50).

According to social identity theory, collective action is likely when three conditions are met (van Zomeren and Iyer, 2009). First, the boundaries between groups should be seen as impermeable, so that members of the low-status group cannot join the high-status group (Kelly, 1993). This applies also, at least partly, to the category of people with disabilities in the case of congenital or incurable impairments. Second, the group's low-status position should be perceived as unjust. And third, the members of the low-status group should perceive their illegitimate position as unstable, meaning that they can take action to improve the situation.

Another important factor for collective action is group efficacy (Mummendey et al., 1999). Group efficacy 'gives people a sense of collective power or strength on the basis of which they believe themselves capable of transforming the situation and destiny of their group' (van Zomeren et al., 2008: 507). The stronger the feeling of group efficacy, i.e., the more a social group feels that its actions matter, the more likely it also is for the group to undertake collective action (Mummendey et al., 1999).

Both the relative deprivation and the social identity theory emphasize the role of group membership and the feelings of unfairness as motivators of collective action. However, they do not differentiate between various forms of political participation. It is quite conceivable that factors that drive people 
into collective action in general may have different effects depending on the type of particular form of participation. One way to approach these differences is to examine various incentives behind the individual's decision to participate or not in specific types of activities.

In political science, Olson's (1965) theory of collective action is undoubtedly the most influential theory used to analyse collective action. The core assumption of his theory is that people participate in collective action only if they can obtain selective incentives through this activity. In addition to material benefits, these incentives may include, for instance, the satisfaction of complying with social norms stressing the importance of political participation, or simply the social benefits that one gets when joining others in purposeful action (Bäck et al., 2011). The important point is that the incentives one obtains from collective action depend on the type of action in question.

We will later come back to these theoretical considerations when we formulate in more detail our framework and the specific hypotheses we test in the empirical analysis. However, before that, it is important to review the notion of discrimination and the results from previous studies analysing how political participation is affected by disabilities.

\section{Discrimination between groups}

The social psychology literature offers a plethora of definitions regarding the notion of discrimination. In his seminal book The Nature of Prejudice, Allport (1954: 51) defined discrimination as refusing 'individuals or groups of people equality of treatment which they may wish'. Recent studies have defined discrimination as behaviour 'directed towards category members that is consequential for their outcomes and that is directed towards them not because of any particular deservingness or reciprocity, but simply because they happen to be members of that category' (Correll et al., 2010: 46). 
Discrimination is not synonymous with prejudice or stereotypes (Al Ramiah et al., 2010). Prejudice refers to a negative attitude towards a member of an out-group, while stereotypes are simplistic generalizations regarding a group of people. Discrimination on the other hand does not remain on the level of attitudes as prejudice does, or on the level of beliefs as stereotypes do: discrimination is a form of behaviour (Al Ramiah et al., 2010). Discriminatory behaviour can develop on the grounds of any social category, e.g., ethnicity, gender or religion. Disability also forms a category towards which discriminatory behaviour can and has been directed.

To explain the causes of discrimination, Tajfel and Turner (e.g., 1979) developed the social identity theory, which holds that each individual has one or more social identities. Social identity is defined as 'the individual's knowledge that he belongs to certain social groups together with some emotional and value significance to him of the group membership' (Tajfel, 1972: 292). The individuals that belong to a social group do not need to have exactly matched characteristics. For example, the social category of people with disabilities does not imply that all individuals who identify with this group must have the same type of disability. Disability is an umbrella concept comprising different types of physical or mental impairment. So, for individuals to have the feeling of group membership it suffices that, regardless of their type of disability, they feel that they are part of a larger group of people with disabilities in which members share similar (yet not necessarily identical) characteristics.

A person can belong simultaneously to many social groups. However, what is important is that a social group 'does not exist in isolation [...] but is only such in contrast with another' (Hogg and Abrams, 1988: 14). For example, the category 'disabled' would not have a particular social meaning unless it was demarcated from the contrasting category of 'non-disabled' or 'healthy'. Tajfel and Forgas (2000: 114) put it lucidly: 'We are what we are, because they are not what we are'. Demarcation between different social categories leads to a comparison that entails two 
intertwined effects: positive evaluation of one's own group (in-group favouritism) and negative evaluation of the groups to which others belong (out-group derogation).

\section{Disability and political participation}

In political science, participation has often been approached from the perspective of resources and social networks. Resources such as good education, civic skills and high income promote participation. Correspondingly, good social relations increase the likelihood of political recruitment. In the case of people with disabilities, many of these aspects may be lacking or at least on a lower level than for citizens in general. Furthermore, disabilities can limit individuals' physical or mental resources, 'often requiring that extra time, effort, and money to compensate for the limitations' (Schur et al., 2002: 169). In this sense, it is quite conceivable that people with disabilities constitute a group that suffers from relative deprivation and unfavourable comparisons to other groups, as the relative deprivation and social identity theories assume.

Previous studies show that problems related to individuals' health conditions depress voting turnout (e.g., Mattila et al., 2013) and other forms of political activities (Peterson, 1987). Studies concentrating particularly on the participation of people with disabilities are mostly conducted in the US. They show that people with disabilities on average report lower levels of both internal and external political efficacy (Gastil, 2000; Schur et al., 2003). They are ialso less likely to perceive the political system as responsive to them, and often, partly due to lower levels of education and civic skills, they feel that they are less qualified to participate in politics.

Studies of voter turnout in the US show that people with disabilities have a turnout rate of three to 20 percentage points lower than the general population, depending on the election and the type of disability (Schur and Adya, 2013; Schur et al., 2002). People with disabilities in the US were also more likely to report that they had a voter registration problem or a problem with the voting 
equipment (Hall and Alvarez 2012). Grammenos (2013) studied (using ESS data) voting activity among people with disabilities in Europe and found a difference of eight percentage points between disabled and non-disabled citizens. The lowest turnout rates within the group of disabled people are found among those who are unemployed and among senior citizens. Interestingly, younger people with disabilities have turnout levels similar to non-disabled people in the same age group (Schur et al., 2005). This development may be related to improved voter facilitation that has taken place in many countries during the past two decades. As, for instance, Vickers and Fraser point out that it was not before 1992 when the 'architectural accessibility of polling stations became mandatory' (1996: 173) in Canada, guaranteeing thus a full access to franchise.

Research on other types of political activities has produced essentially similar results. In the US people with disabilities are less likely to participate in political activities, e.g., to attend political meetings or to give support to political candidates (Schur and Adya, 2013; Schur et al., 2005; Schur, 2003). However, there are some notable exceptions. People with disabilities are as likely as non-disabled persons to contact public officials (Schur and Adya, 2013: 818). Furthermore, there are some interesting gender differences. Although women with disabilities are in general less likely to participate, they are more likely to participate in protests or marches than women without disabilities (Schur, 2003: 31). Furthermore, they are more inclined to take action against perceived discrimination. Results from Europe show that, overall, persons with disabilities are as interested in politics as the general population and they have similar levels of trust in political institutions (FRA, 2014: 31)

\section{Hypotheses}

The social psychological theories reviewed above assume that individuals who identify with a disadvantaged group and who feel resentment about their group's situation should be motivated to 
participate in collective action. However, as the previous review of empirical studies shows, in general disabilities tend to decrease participation. If the theory is correct, this discrepancy can be explained by the fact that most people with disabilities do not feel that they form a coherent group or, even if they do, they do not necessarily feel enough resentment about their situation. We assume that those persons with disabilities who also perceive discrimination against themselves because of their disability are more likely to exhibit both characteristics needed for participation: group identity and resentment of their situation. Thus, we hypothesize first that participation is lower among people with disabilities than in the general population. However, among people with disabilities, those who perceive discrimination against the group of disabled people are more active than those who do not perceive such discrimination.

We concentrate on three types of participation: voting, contacting politicians or government officials, and taking part in lawful demonstrations. The social identity theory does not give precise predictions on how group identity and resentment affect different types of participation. Thus, we rely here on theories of collective action from political science. Political participation is more likely if the activity rewards the participants with some kind of psychological reward (Bäck et al., 2011). One of these rewards is the satisfaction received from complying with social norms. Political participation in general is valued in the society and this particularly applies to voting. Thus, it is not surprising that voting is usually the most common form of political participation among people with or without disabilities.

However, among people with disabilities the relationship between general societal norms and political participation may be more complex. According to Anspach (1979), persons with disabilities and a positive self-concept of themselves may adopt two different strategies in relation to political participation. Those adopting a normalisation strategy aim to participate in societal activities following the general norms of the wider society. Others may adopt a strategy of political activism which challenges the prevailing views of people with disabilities as passive and dependent. 
Nonetheless, both strategies stress the importance of political participation, either as a 'normal' person or as an activist. However, in addition to voting, the strategy of political activism entails a broader variety of participation forms (e.g. demonstrating) than the normalisation strategy (see Schur et al., 2013: 94-95).

The likelihood of participating is also affected by the power to set the agenda (Verba and Nie, 1987). Contacting public officials and participating in demonstrations are forms of participation where the participants can choose the agenda: they can contact public officials in the context of their own specific problems or participate in demonstrations where the issue is particularly important to them. In contrast, voting takes place in an environment which is mostly defined by the politicians, the parties and the media, not by the individual. The power to set the agenda is also directly linked to perceived individual or group political efficacy. Freedom to influence the agenda is likely to be connected to increased levels of efficacy as the participants can more freely choose the form of participation in which they perceive their influence to be greatest either by acting as individual citizens (Abramson and Aldrich, 1982) or as members of a social group. Consequently, we expect group identity and resentment among people with disabilities to produce more sizeable mobilizing effects on contacting and demonstrating than on turning out to vote.

Participation in collective action also provides social benefits, that is, rewards from working together with other persons with similar political goals. While voting is an act that one can perform alone, participating in demonstrations is clearly a group-based action (Bäck et al., 2011). Contacting public officials or politicians can take place jointly with others or by a single person alone. Thus, we assume that the social benefits are highest for demonstrating, lower for contacting and lowest for voting.

Based on these theoretical considerations, we can formulate our second hypothesis. Unlike voting, contacting public officials and demonstrating give participants the freedom to set the agenda. 
Likewise, the social benefits are higher for demonstrating than for voting. Contacting is somewhere between these two activities. Combining these differences in benefits with our first hypothesis, we assume that the effect of group identity and resentment produces more sizeable effects for demonstrating than for contacting and the effect is smallest for voting. In practical terms, this means that we expect that disability combined with perceived discrimination is more likely to mobilize people into non-institutionalized forms of political participation than to vote in elections.

\section{Data}

In the empirical analysis, we use European Social Survey (ESS 2012) data which cover 32 European states ${ }^{2}$ and six survey rounds during 2002-2012. Each ESS round is based on random samples of persons aged 15 and over with national sample sizes of approximately 1,500 , or 800 in countries with populations less than a million. In our analysis we include only respondents who were eligible to vote at the time of the survey.

As dependent variables in our analyses we use three different forms of political participation. The first one is voting, which was inquired about in the survey with the following question: 'Some people don't vote nowadays for one reason or another. Did you vote in the last [country] national election in [month/year]?' Contacting was asked about in the following way: 'There are different ways of trying to improve things in [country] or help prevent things from going wrong. During the last 12 months, have you done any of the following: Have you contacted a politician, government or local government official? ${ }^{33}$ The question relating to demonstrating began with the same opening and then asked: 'Have you taken part in a lawful public demonstration?' All these variables were coded as a dichotomy where 1 indicated that the respondent answered 'yes', otherwise it was 0 .

In our main independent variable we have categorized the respondents into three groups based on their disability status and whether they have been discriminated against because of their disability. 
The groups are 1) non-disabled, 2) disabled but not discriminated against and 3) disabled and discriminated against. We used two survey questions to construct these groups. The first question asked about their health status: 'Are you hampered in your daily activities in any way by any longstanding illness, or disability, infirmity or mental health problem?' The same question, or similarly worded questions in other surveys, has been used to differentiate between disabled and non-disabled persons in previous studies (e.g., Grammenos, 2013). With this question it is possible to differentiate between those who we classify as belonging to groups 2 or 3 (disabled) and group 1 (non-disabled).

The second question enables us to make a differentiation between groups 2 and 3 . The question was formulated as follows: 'Would you describe yourself as being a member of a group that is discriminated against in this country? On what grounds is your group discriminated against?' The respondents who answered this question by referring to their disability were coded as belonging to group 3. This question is very suitable for our purposes because it captures both the identification with the group of disabled and perceived discrimination which in all likelihood leads to feelings of resentment for the unjust position of the group. It should, however, be stressed that although perceiving oneself to be 'a member of a group that is discriminated against in this country' is not the same as actually personally experiencing discrimination in everyday life, they can both lead to feelings of resentment that the group is being treated unfairly by the others.

Although it would be interesting to study the effect of disability-based discrimination on political participation in each of the 32 countries separately, the reported small number of people with disabilities and discrimination experiences in some countries renders this impossible. To solve this problem we aggregated the waves of the ESS data pooling together observations from 32 countries. Thus we generated a large sample of around 270,000 respondents that matters the most in our case since this is the sample at level of which our main independent variable is measured in the multilevel analysis. Regarding our main independent variable the overwhelming majority of the 
respondents, 216,343 or almost $75 \%$, belong to group 1 (non-disabled) and nearly $25 \%$ of the respondents or 72,145 individuals belong to group 2 (disabled but not discriminated against). The respondents who belong to group 3 (disabled and discriminated), amount to just $0.53 \%$. Although this percentage is quite small, it still corresponds to 1,536 individuals, a sufficient number for an analysis of categorical dependent variables with several predictors. It is also important to note that the average cluster sizes (that is the number of disabled people who are discriminated in each of the 32 countries) is not important ${ }^{4}$ for the power of our test (Snijders, 2005). What is important in this case is the sample size at the individual level that mounts to 1,536 cases. While the group of persons discriminated against because of their disability is small compared to the two other groups, we feel that the analysis is justified since we are primarily interested in the study of the theoretical mechanisms that promote participation among people with disabilities. However, at the same time we also acknowledge that the small number of individuals in this group means that our results should be interpreted with great caution.

As demographic control variables we use age, age squared and gender. Controlling for age is important as both disabilities and participation are strongly affected by age. In addition, the models include respondents' education which is also associated with political participation (e.g., Marien et al., 2009). We also control for social connectedness with a variable that indicates whether the respondent lives together with a spouse. Models in which voting is the dependent variable include also a dummy variable indicating whether voting in the country is compulsory as this is likely to increase the overall turnout rate.

The inclusion of such mediating variables as interest in politics or personal efficacy in the models is a more complicated matter. If we think that these two factors are located between disability and discrimination perceptions and the dependent variables in the 'causal chain', controlling for them would introduce post-treatment bias in the analysis and reduce the estimates of the total effect of disability/discrimination on participation. However, it is also possible that efficacy and, especially, 
interest in politics causally precedes perceptions of discrimination as those who follow politics more carefully are also more likely to recognise discriminatory acts or practices. Thus, we present two sets of models and control for political interest and efficacy in the second set of analyses.

Political interest is measured with a variable that varies between 1-4 and where bigger values indicate stronger interest. Efficacy was measured with a question 'How often does politics seem so complicated that you can't really understand what is going on?'. This question had five answer categories ranging from 'Never' to 'Frequently'. However, a major problem with the efficacy question is that it was not included in the ESS questionnaire in $5^{\text {th }}$ and $6^{\text {th }}$ waves. Thus the results where this variable is included are not directly comparable to results obtained with all ESS waves included. These results, nevertheless, serve as robustness checks which allow us to judge the overall change in our main explanatory variables when efficacy and interest are included.

Before moving to present the results of our analysis, a note should be taken regarding the limitations of the study arising from the wording of the questions in the ESS survey. The data do not distinguish the source of perceived discrimination when asking people 'On what grounds is your group discriminated against?' When a respondent answers that (s)he perceives discrimination on the grounds of disability, it is not possible for us to know if discrimination stems from the behaviour of individuals (individual discrimination) or from policies ${ }^{5}$ and practices that are carried out by governmental institutions (institutional discrimination). Although the distinction between individual and institutional perceived discrimination has important implications, we believe nevertheless that our first hypothesis does not change substantively: disabled voters are more likely to adopt more collective forms of action when they feel that they are being discriminated against (regardless of the source of perceived discrimination).

Another wording issue relates to the fact that the ESS data do not provide any information regarding the type of contact between the respondent and the politician, government or local government 
official. Contact can take different forms: for example, a person can contact a politician face-toface, or by phone, e-mail etc. The first form of contact is more direct or personal compared to the latter two, and in that sense it might be deemed more effective. So although contacting can be demarcated from voting with respect to giving more freedom to the participants to set the agenda, nevertheless we acknowledge that different types of contact can potentially affect the feeling of group efficacy. Lastly, it should be acknowledged that there is an issue of temporality that cannot be addressed with the ESS data. That is, people with disabilities are more likely to recognize elements of discrimination when they join activist groups even if the reason for their participation in these groups might be related to other issues such as e.g. access to benefits etc. This is a limitation of the study and is must be kept in mind when the implication of the results are assessed.

\section{Results}

We use multilevel logistic regression analysis to study our hypotheses. More specifically, we use a random intercept model where the intercept is allowed to vary between the 32 countries included in the ESS data. The results for the three types of participation are presented in Table 1. For each three forms of participation we present two models. In the first model, we do not include the variables measuring interest and efficacy for the reasons explained in the previous section. In the second model, these two variables are added. We also tested the same models with a fixed effects specification (i.e. with country dummies) but the results remain very similar to those obtained with the random intercept model and they lead to same overall conclusions.

\section{[TABLE 1 HERE]}

In Table 1 the control variables behave as expected. All forms of participation first increase with age, and later in life the participation level stabilizes and then starts to decline in old age. For voting and contacting the levels of participation are highest among 50-65-year-olds, while for 
demonstrating the peak comes as early as ages 30-40 and starts to decline thereafter. High levels of education and strong social relations also foster involvement in all three forms of participation. The inclusion of interest in politics and political efficacy do not change the coefficients for the disability and discrimination dummies markedly, except in the case of demonstrating when the dummy for disability with no discrimination is no longer statistically significant. The results in the upper part of Table 1 indicate that people with disabilities are less likely to vote than non-disabled persons and people with disabilities who have perceived discrimination against their own group are even less likely to turn out in the polls. This result is the direct opposite of what our first hypothesis expected. However, when looking at contacting and demonstrating, the results are to some extent more consistent with the hypothesis. People with disabilities do contact politicians and demonstrate more often than those with no disabilities, and feelings of perceived group discrimination further increase this tendency. Thus, the first hypothesis was only partially supported by these findings.

The results in Table 2 show the estimated probability of engaging in each type of participation for respondents in the three groups after adjusting for the control variables (calculated from the models with all ESS waves included). The table shows both the estimated level of participation and the difference between the groups and the reference group (people with no disabilities). For example, the estimated probability of a non-disabled person voting is $80 \%$, while the corresponding probability for those with both disability and experiences of discrimination is $75 \%$. The difference is thus five percentage points in favour of the non-disabled. This difference is also statistically significant at the $\mathrm{p}<0.01$ level. The turnout for people with disabilities but no experiences of perceived discrimination is $77 \%$. Thus, disabilities lower voting activity, and disability combined with perceived discrimination lowers it further.

\section{[TABLE 2 HERE]}


For contacting and demonstrating, the effects of disability and/or perceived discrimination work in the opposite way. For non-disabled persons the estimated probability of contacting politicians is 12 $\%$, while for those who have perceived group discrimination the probability is over twice as high, $26 \%$. The level of participation in demonstrations for non-disabled and people with disabilities but no experience of perceived discrimination is about the same, 5-6\%. However, for those who have perceived discrimination the participation level of demonstrating is notably higher, i.e., $9 \%$.

Overall, these results give only partial support for our two hypotheses. The first hypothesis predicted that, when compared to the group of non-disabled, participation is lower among persons with disabilities, but increases when disability is combined with perceived group discrimination. This is not the case with voting, which decreases even further when a person with a disability also has perceived discrimination. In contrast, perceived discrimination increases the likelihood of demonstrating and contacting politicians or government officials.

The second hypothesis assumed that perceived discrimination would have the largest mobilizing effects on demonstrating and contacting, and a smaller effect on voting. This hypothesis is partially supported as perceived discrimination clearly increases the likelihood of contacting and demonstrating, but, on the other hand, the effect on turnout is actually the reverse. This finding is likely to be connected to the varying benefits available from different types of participation. Contacting politicians and taking part in demonstrations gives the participants the freedom to choose their own agenda, which is probably associated with enhanced feelings of group efficacy. Furthermore, these two activities provide participants with more 'social' benefits than voting, which may be an important factor in the formation of group identity needed for collective action according to social psychology theories.

\section{Conclusions}


In this study we analysed how perceived discrimination affects different forms of political participation by people with disabilities. The study put forward two main hypotheses. The first held that although political participation is lower for people with disabilities than for the general population, those people who are discriminated against because of disability will nonetheless be more prone to undertake collective action compared to those who perceived no discrimination. The second hypothesis asserted that the sense of group identity along with feelings of resentment on the part of people with disabilities would produce more sizeable effects for demonstrating than for contacting, and the effect would be smallest for voting.

Results supported the assertion that people with disabilities are less likely to turn out to vote in comparison to people with no disabilities, and that perceived discrimination amplifies this trend. Yet, although disability is associated with lower turnout, it has the opposite effect on the other two forms of political participation, namely taking part in demonstrations and contacting politicians or government officials. Interestingly enough, perceived discrimination is not a hindrance to demonstrating and contacting; it may actually induce these forms of political participation. This result is in line with previous studies (e.g. Anspach, 1979; Shapiro, 1993). Anspach (1979) recognizes an increased level of political activism among the physically disabled or former psychiatric patients as a means of renouncing the social stigma. In the same vein, Shapiro (1993) shows that it was the shared experience of discrimination among people with disabilities that made them mobilize ${ }^{6}$ towards forming the independent living movement that emerged during the 1960s and 1970s-80s in the US and Europe, respectively.

It is, however, important to remember that the relationship between the 'politicisation' and perceptions of discrimination among people with disabilities can be two-sided. Politically engaged individuals with disabilities may be more likely to recognise discrimination in their everyday life than those who participate less (Schur et al., 2013: 100-101). Thus, our results, based on repeated 
cross-sectional surveys, do not enable us to take a strong position on the causal direction of the effect, which is a clear limitation of our analysis.

Why is it, then, that perceived disability-based discrimination seems to encourage some forms of political participation, but not others? A person with disabilities who is subject to discrimination is more likely to adopt forms of action supported by a salient group identity (Hogg and Abrams, 1988). This is especially true in the case of demonstrations, and can also be true with regard to contacting politicians. The necessary condition in the latter case is that the persons do not contact public officials with the goal of securing or restoring individual benefits but make the contact to promote the interests of the group to which they belong i.e., people with disabilities. As we saw when discussing the social identity theory, the feeling of group efficacy is an important factor in collective action. Group efficacy is enhanced by the freedom to set the agenda, especially in cases where an issue does not fall within the boundaries of the mainstream political discourse, as is the case with discrimination against people with disabilities. As voting hardly gives the opportunity for any social group to unilaterally set the agenda of the elections, it is reasonable to assume that the more issue-oriented a group is, the more likely it also is that its members will prefer to use forms of action in which the chances to make a difference are high. However, the emphasis on noninstitutionalised forms of participation may also be related to questions of necessity. In many countries possibilities for voting for people with disabilities are restricted legally or practically (difficulties of access to voting). Hence, when denied a legitimate form of participation people with disabilities may choose to use more direct forms of participation instead.

From the policymaking perspective these findings underlie the importance of providing, along with voting facilitation mechanisms, the necessary conditions that will aid the pursuance of forms of political actions such as participating in peaceful demonstrations or contacting politicians among people with disabilities. For example, public transport should be adjusted to assist people with 
disabilities when they have scheduled a public demonstration. Also, politicians and civil servants should make their offices accessible for people with disabilities, equip their offices with e.g. hearing impaired devices in order to facilitate contact with people that suffer from hearing impairment. In reference to voting turn out there is an immense need to move towards eradicating de facto disenfranchisement that emanates from difficulties that people with disabilities face towards accessing the voting booth or using the voting machines. 


\section{References}

Abramson, Richard Paul and John H Aldrich (1982) The decline of electoral participation in America. American Political Science Review 76(3): 502-521.

Al Ramiah, Ananthi, Miles Hewstone, John F Dovidio and Louis Penner (2010) The social psychology of discrimination: Theory, measurement and consequences. In Laurence Bond and Helen Russell (eds) Making equality count: Irish and international approaches to measuring discrimination. Dublin: Liffey Press, 84-112.

Allport, Willard Gordon (1954) The Nature of Prejudice. Reading, MA: Addison-Wesley.

Altman, Barbara (2001) Disability definitions, models, classification schemes, and applications. In Gary L Albrecht, Katherine D Seelman and Michael Bury (eds) Handbook of Disability Studies. London: Sage Publications, 97-122.

Anspach, Renee (1979) From stigma to identity politics: Political activism among the physically disabled and former mental patients. Social Science \& Medicine 13(1): 765-773.

Birt, Catherine and Kenneth L Dion (1987) Relative deprivation theory and responses to discrimination in a gay male and lesbian sample. British Journal of Social Psychology 26(2): 139145.

Bäck, Hanna, Jan Teorell and Anders Westholm (2011) Explaining modes of participation: A dynamic test of alternative rational choice models. Scandinavian Political Studies 34(1): 74-97.

Correll, Joshua, Charles M Judd, Bernadette Park and Bernd Wittenbrink (2010) Measuring prejudice, stereotypes and discrimination. In John F Dovidio, Miles Hewstone, Peter Glick and Victoria M Esses (eds) The Sage Handbook of Prejudice, Stereotyping, and Discrimination. Thousand Oaks, CA: Sage, 45-63.

Della Porta, Donatella and Mario Diani (2006): Social Movements. An Introduction. Oxford: Blackwell.

Driedger, Diane (1989) The Last Civil Rights Movement: Disabled People's International. C Hurst \& Co Publishers Ltd.

ESS (2012): European Social Survey Rounds 1-6 Data. Norwegian Social Science Data Services, Norway - Data Archive and distributor of ESS data.

FRA (2014): The right to political participation for persons with disabilities: human rights indicators. FRA European Agency for Fundamental Rights. Luxembourg: Publications Office of the European Union. 
Gastil, John (2000) The political beliefs and orientations of people with disabilities. Social Science Quarterly 81(2): 588-603.

Grammenos, Stefanos (2013) Task 6: Comparative data and indicators. European comparative data on People with disabilities and Citizenship, Academic Network of European Disability Experts (ANED), December 2013.

Gregory, Susan (1996) The disabled self. In Margaret Wetherell (ed) Identities, Groups and Social Issues. London: Sage publications, 354-261.

Hall Thad and Michael R Alvarez (2012) Defining the barriers to political participation for individuals with disabilities. The information Technology and innovation foundation: Accessible voting technology initiative. Working paper series.

Hogg, Michael and Dominic Abrams (1988) Social Identifications: A Social Psychology of Intergroup Relations and Group Processes. London: Routledge.

Kelly, Caroline (1993) Group identification, intergroup perceptions and collective action. European Review of Social Psychology 4(1): 59-83.

Kelly, Caroline and Sara Breinlinger (1996) The Social Psychology of Collective Action: Identity, Injustice and Gender. London: Taylor and Francis.

Marien, Sofie, Marc Hooghe and Ellen Quintelier (2009) Inequalities in non-institutionalised forms of political participation: A multi-level analysis of 25 countries. Political Studies 58(1): 187-213.

Mattila, Mikko, Peter Söderlund, Hanna Wass and Lauri Rapeli (2013) Healthy voting: the effect of self-reported health on turnout in 30 countries. Electoral Studies 32(4): 886-891.

Mummendey, Amélie, Thomas Kessler, Andreas Klink and Rosemarie Mielke (1999) Strategies to cope with negative social identity: Predictions by social identity theory and relative deprivation theory. Journal of Personality and Social Psychology 76(2): 229-245.

Olson, Mancur (1965) The Logic of Collective Action. Public Goods and the Theory of Groups, Cambridge: Harvard University Press.

Peterson, Steven (1987) Biosocial predictors of older Americans' political participation. Politics and the Life Sciences 5(2): 246-225.

Schur, Lisa (2003) Contending with the "double handicap": Political activism among women with disabilities. Women and Politics 25(1/2): 31-62.

Schur, Lisa and Meera Adya (2013) Sidelined or mainstreamed? Political participation and attitudes of people with disabilities in the United States. Social Science Quarterly 94(3): 811-839. 
Schur, Lisa, Todd Shields and Kay Schriner (2003) Can I make a difference? Efficacy, employment, and disability. Political Psychology 24(1): 119-149.

Schur. Lisa, Todd Shields and Kay Schriner (2005) Generational cohorts, group membership, and political participation by people with disabilities. Political Research Quarterly 58(3): 487-496.

Schur, Lisa, Douglas Kruse and Peter Blanck (2013) People with Disabilities. Sidelined or Mainstreamed?. Cambridge: Cambridge University Press.

Schur, Lisa, Todd Shields, Douglas Kruse and Kay Schriner (2002) Enabling democracy: Disability and voter turnout. Political Research Quarterly 55(1): 167-190.

Shapiro, Joseph (1993) No pity: People with disabilities forging a new civil rights movement. New York: Times Books.

Smith, Jean Heather, Thomas F Pettigrew, Gina M Pippin and Silvana Bialosiewicz (2012) Relative deprivation: A theoretical and meta-analytic review. Personality and Social Psychology Review 16(3): 203-232.

Snijders, Tom (2005) Power and Sample Size in Multilevel Linear Models. In Brian S Everitt and David C Howell (eds) Encyclopedia of Statistics in Behavioral Science. Volume 3. Wiley, 2005, 1570-1573.

Tajfel, Henri (1972) Social categorization. [English manuscript of 'La catégorisation sociale']. In Serge Moscovici (ed) Introduction à la Psychologie Sociale. Paris: Larousse, 272-302.

Tajfel, Henri and Joseph P Forgas (2000) Social categorization: Cognitions, values and groups. In Charles Strangor (ed.) Stereotypes and Prejudice. Philadelphia, PA: Psychology Press, 113-140.

Tajfel, Henri and John Turner (1979) An integrative theory of intergroup conflict. In William G. Austin and Stephen Worchel (eds) The Social Psychology of Inter-Group Relations. Monterey: CA, Brooks/Cole, pp. 33-47.

Turner, Charles John, Michael A Hogg, Penelope J Oakes, Stephen D Reicher and Margaret S Wetherell (1987) Rediscovering the Social Group: A Self-Categorization Theory. New York: Basil Blackwood Ltd.

Valentine, Fraser and Jill Vickers (1996) Released from the Yoke of Paternalism and Charity: Citizenship and the Rights of Canadians with Disabilities. International Journal of Canadian Studies 14: 155-177.

Verba, Sidney and Norman H Nie (1987) Participation in America. Political Democracy and Social Equality. Chicago: University of Chicago Press. 
van Zomeren, Martijn and Aarti Iyer (2009) Introduction to the social and psychological dynamics of collective action. Journal of Social Issues 65(4): 645-660.

van Zomeren, Martijn, Tom Postmes and Russell Spears (2008) Toward an integrative social identity model of collective action: A quantitative research synthesis of three socio-psychological perspectives. Psychological Bulletin 134(4): 504-535.

Walker, Lain and Leon Mann (1987) Unemployment, relative deprivation, and social protest. Personality and Social Psychology Bulletin 13(2): 275-283.

World Health Organization (2011) World Report on Disability. Geneva: WHO.

Wright, Stephen (2009) The Next Generation of Collective Action Research. Journal of Social Issues 65(4): 859-879. 
Table 1. Multilevel logistic regression of three participation forms (standard errors in parentheses, ${ }^{* *} \mathrm{p}<0.01$, $* \mathrm{p}<0.05)$.

\begin{tabular}{|c|c|c|c|c|c|c|}
\hline & \multicolumn{2}{|c|}{ Voting } & \multicolumn{2}{|c|}{ Contacting } & \multicolumn{2}{|c|}{ Demonstrating } \\
\hline $\begin{array}{l}\text { Disabled without } \\
\text { perceptions of group } \\
\text { discrimination }\end{array}$ & $\begin{array}{c}-0.21 * * \\
(0.01)\end{array}$ & $\begin{array}{c}-0.21^{* *} \\
(0.02)\end{array}$ & $\begin{array}{l}0.22 * * \\
(0.01)\end{array}$ & $\begin{array}{c}0.23 * * \\
(0.02)\end{array}$ & $\begin{array}{c}0.06 * * \\
(0.02)\end{array}$ & $\begin{array}{c}0.04 \\
(0.03)\end{array}$ \\
\hline $\begin{array}{l}\text { Disabled with } \\
\text { perceptions of group } \\
\text { discrimination }\end{array}$ & $\begin{array}{c}-0.32 * * \\
(0.06)\end{array}$ & $\begin{array}{c}-0.41^{* *} \\
(0.08)\end{array}$ & $\begin{array}{c}0.95^{* *} \\
(0.06)\end{array}$ & $\begin{array}{c}0.91 * * \\
(0.08)\end{array}$ & $\begin{array}{c}0.50 * * \\
(0.10)\end{array}$ & $\begin{array}{l}0.36^{* *} \\
(0.13)\end{array}$ \\
\hline Interest in politics & - & $\begin{array}{c}0.61^{* *} \\
(0.01) \\
\end{array}$ & - & $\begin{array}{c}0.57^{* *} \\
(0.01) \\
\end{array}$ & - & $\begin{array}{c}0.63 * * \\
(0.01) \\
\end{array}$ \\
\hline Low internal efficacy & - & $\begin{array}{c}-0.07 * * \\
(0.01)\end{array}$ & - & $\begin{array}{c}-0.08 * * \\
(0.01)\end{array}$ & - & $\begin{array}{c}-0.07^{* *} \\
(0.01)\end{array}$ \\
\hline $\begin{array}{l}\text { Educ: lower } \\
\text { secondary }\end{array}$ & $\begin{array}{c}0.09 * * \\
(0.02)\end{array}$ & $\begin{array}{c}-0.11 * * \\
(0.03)\end{array}$ & $\begin{array}{c}0.25^{* *} \\
(0.03)\end{array}$ & $\begin{array}{c}0.10^{* *} \\
(0.03)\end{array}$ & $\begin{array}{c}0.44 * * \\
(0.04)\end{array}$ & $\begin{array}{c}0.26 * * \\
(0.05) \\
\end{array}$ \\
\hline $\begin{array}{l}\text { Educ: upper } \\
\text { secondary }\end{array}$ & $\begin{array}{c}0.49 * * \\
(0.02) \\
\end{array}$ & $\begin{array}{c}0.16^{* *} \\
(0.03) \\
\end{array}$ & $\begin{array}{c}0.55^{* *} \\
(0.02) \\
\end{array}$ & $\begin{array}{c}0.28^{* *} \\
(0.03) \\
\end{array}$ & $\begin{array}{c}0.71^{* *} \\
(0.04) \\
\end{array}$ & $\begin{array}{l}0.36^{* *} \\
(0.04) \\
\end{array}$ \\
\hline $\begin{array}{l}\text { Educ: post- } \\
\text { secondary }\end{array}$ & $\begin{array}{c}0.76^{* *} \\
(0.03)\end{array}$ & $\begin{array}{c}0.41^{* *} \\
(0.05)\end{array}$ & $\begin{array}{c}0.75^{* *} \\
(0.04)\end{array}$ & $\begin{array}{c}0.44 * * \\
(0.05)\end{array}$ & $\begin{array}{c}0.86 * * \\
(0.05)\end{array}$ & $\begin{array}{l}0.42^{* *} \\
(0.07)\end{array}$ \\
\hline Educ: tertiary & $\begin{array}{l}1.00 * * \\
(0.02)\end{array}$ & $\begin{array}{c}0.45^{* *} \\
(0.03)\end{array}$ & $\begin{array}{c}1.09 * * \\
(0.02)\end{array}$ & $\begin{array}{c}0.62 * * \\
(0.03)\end{array}$ & $\begin{array}{l}1.25^{* *} \\
(0.04)\end{array}$ & $\begin{array}{l}0.65^{* *} \\
(0.04) \\
\end{array}$ \\
\hline Age & $\begin{array}{c}0.08^{* *} \\
(0.00)\end{array}$ & $\begin{array}{c}0.08^{* *} \\
(0.00)\end{array}$ & $\begin{array}{c}0.08 * * \\
(0.00)\end{array}$ & $\begin{array}{c}0.07 * * \\
(0.00)\end{array}$ & $\begin{array}{c}0.01 * * \\
(0.00)\end{array}$ & $\begin{array}{l}-0.00 \\
(0.00)\end{array}$ \\
\hline Age $^{2}$ & $\begin{array}{c}-0.00 * * \\
(0.00)\end{array}$ & $\begin{array}{c}-0.00 * * \\
(0.00)\end{array}$ & $\begin{array}{c}-0.00 * * \\
(0.00)\end{array}$ & $\begin{array}{c}-0.00 * * \\
(0.00)\end{array}$ & $\begin{array}{c}-0.00 * * \\
(0.00)\end{array}$ & $\begin{array}{c}-0.00 * * \\
(0.00)\end{array}$ \\
\hline Gender (1=female) & $\begin{array}{c}-0.01 \\
(0.01)\end{array}$ & $\begin{array}{c}0.14^{* *} \\
(0.01)\end{array}$ & $\begin{array}{c}-0.35^{* *} \\
(0.01)\end{array}$ & $\begin{array}{c}-0.18 * * \\
(0.01)\end{array}$ & $\begin{array}{c}-0.21 * * \\
(0.02)\end{array}$ & $\begin{array}{c}0.01 \\
(0.02) \\
\end{array}$ \\
\hline Co-habitation & $\begin{array}{c}0.37 * * \\
(0.01) \\
\end{array}$ & $\begin{array}{c}0.35^{* *} \\
(0.01) \\
\end{array}$ & $\begin{array}{c}0.14^{* *} \\
(0.01)\end{array}$ & $\begin{array}{c}0.15^{* *} \\
(0.02) \\
\end{array}$ & $\begin{array}{c}-0.25 * * \\
(0.02)\end{array}$ & $\begin{array}{c}-0.27^{* *} \\
(0.02)\end{array}$ \\
\hline Compulsory voting & $\begin{array}{l}0.59 * \\
(0.30)\end{array}$ & $\begin{array}{l}0.74 * * \\
(0.32)\end{array}$ & - & - & - & - \\
\hline ESS-round2 & $\begin{array}{c}-0.14 * * \\
(0.02)\end{array}$ & $\begin{array}{c}-0.10 * * \\
(0.02) \\
\end{array}$ & $\begin{array}{c}-0.13 * * \\
(0.02)\end{array}$ & $\begin{array}{c}-0.12 * * \\
(0.02)\end{array}$ & $\begin{array}{c}0.02 \\
(0.03) \\
\end{array}$ & $\begin{array}{c}0.02 \\
(0.03) \\
\end{array}$ \\
\hline ESS-round3 & $\begin{array}{c}-0.15^{* *} \\
(0.02)\end{array}$ & $\begin{array}{c}-0.09 * * \\
(0.02)\end{array}$ & $\begin{array}{c}-0.12 * * \\
(0.02)\end{array}$ & $\begin{array}{c}-0.08 * * \\
(0.02)\end{array}$ & $\begin{array}{c}-0.19 * * \\
(0.03)\end{array}$ & $\begin{array}{c}-0.22 * * \\
(0.03) \\
\end{array}$ \\
\hline ESS-round4 & $\begin{array}{c}-0.12 * * \\
(0.02)\end{array}$ & $\begin{array}{c}-0.08 * * \\
(0.02)\end{array}$ & $\begin{array}{c}-0.20 * * \\
(0.02)\end{array}$ & $\begin{array}{c}-0.18 * * \\
(0.02)\end{array}$ & $\begin{array}{c}-0.21 * * \\
(0.03)\end{array}$ & $\begin{array}{c}-0.21^{* *} \\
(0.03)\end{array}$ \\
\hline ESS-round5 & $\begin{array}{c}-0.20 * * \\
(0.02)\end{array}$ & - & $\begin{array}{c}-0.21^{* *} \\
(0.02)\end{array}$ & - & $\begin{array}{c}-0.21 * * \\
(0.03)\end{array}$ & - \\
\hline ESS-round6 & $\begin{array}{c}-0.25^{* *} \\
(0.02)\end{array}$ & - & $\begin{array}{c}-0.27^{* *} \\
(0.02)\end{array}$ & - & $\begin{array}{l}-0.02 \\
(0.03)\end{array}$ & - \\
\hline Intercept & $\begin{array}{c}-1.67 * * \\
(0.11)\end{array}$ & $\begin{array}{c}-2.48 * * \\
(0.13)\end{array}$ & $\begin{array}{c}-4.12 * * \\
(0.10)\end{array}$ & $\begin{array}{c}-4.84 * * \\
(0.12)\end{array}$ & $\begin{array}{c}-3.15 * * \\
(0.14)\end{array}$ & $\begin{array}{c}-3.86 * * \\
(0.17)\end{array}$ \\
\hline $\begin{array}{l}\text { Random effect: } \\
\text { Intercept (sd) }\end{array}$ & 0.56 & 0.59 & 0.46 & 0.46 & 0.70 & 0.70 \\
\hline Log likelihood & $-123,137$ & $-70,845$ & $-103,461$ & $-64,772$ & $-59,597$ & $-36,793$ \\
\hline $\mathrm{N}$ & 260,788 & 162,978 & 275,176 & 171,714 & 275,056 & 171,632 \\
\hline
\end{tabular}

Reference groups: Disability (non-disabled), Education (less than lower secondary). 
Table 2. Estimated probability and change in probability of voting, contacting politicians or government officials and taking part in lawful demonstrations (standard errors in parentheses).

\begin{tabular}{|c|c|c|c|c|c|c|}
\hline & \multicolumn{2}{|c|}{ Voting } & \multicolumn{2}{|c|}{ Contacting } & \multicolumn{2}{|c|}{ Demonstrating } \\
\hline & Probability & $\begin{array}{l}\text { Change in } \\
\text { probability }^{\text {a }}\end{array}$ & Probability & $\begin{array}{l}\text { Change in } \\
\text { probability }^{\text {a }}\end{array}$ & Probability & $\begin{array}{l}\text { Change in } \\
\text { probability }\end{array}$ \\
\hline Non-disabled & $\begin{array}{l}0.80 \\
(0.01)\end{array}$ & & $\begin{array}{l}0.12 \\
(0.01)\end{array}$ & & $\begin{array}{c}0.05 \\
(0.01)\end{array}$ & \\
\hline $\begin{array}{l}\text { Disabled without } \\
\text { perceptions of } \\
\text { discrimination }\end{array}$ & $\begin{array}{c}0.77 \\
(0.02)\end{array}$ & $\begin{array}{c}-0.03^{* *} \\
(0.00)\end{array}$ & $\begin{array}{c}0.15 \\
(0.01)\end{array}$ & $\begin{array}{c}+0.02^{* *} \\
(0.00)\end{array}$ & $\begin{array}{c}0.06 \\
(0.01)\end{array}$ & $\begin{array}{c}+0.003^{* *} \\
(0.00)\end{array}$ \\
\hline $\begin{array}{l}\text { Disabled with } \\
\text { perceptions of } \\
\text { discrimination }\end{array}$ & $\begin{array}{l}0.75 \\
(0.02)\end{array}$ & $\begin{array}{c}-0.05^{* *} \\
(0.01)\end{array}$ & $\begin{array}{c}0.26 \\
(0.02)\end{array}$ & $\begin{array}{c}+0.14^{* *} \\
(0.00)\end{array}$ & $\begin{array}{c}0.09 \\
(0.01)\end{array}$ & $\begin{array}{c}+0.03 * * \\
(0.01)\end{array}$ \\
\hline
\end{tabular}

${ }^{a}$ Compared to the group of non-disabled. ${ }^{*} \mathrm{p}<0.05,{ }^{* *} \mathrm{p}<0.01$

\footnotetext{
${ }^{1}$ However, it is important to note that disability does not always require a functional limitation. Some conditions, such as cancer, are generally considered to be disabilities even though they do not necessarily create functional limitations.

${ }^{2}$ Austria, Belgium, Bulgaria, Croatia, Cyprus, Czech Republic, Denmark, Estonia, Finland, France, Germany, Greece, Hungary, Iceland, Ireland, Israel, Italy, Lithuania, Luxembourg, Netherlands, Norway, Poland, Portugal, Russian Federation, Slovakia, Slovenia, Spain, Sweden, Switzerland, Turkey, Ukraine, United Kingdom.

${ }^{3}$ The opening of the question stresses the collective nature of participation. It is, however, important to remember that many people with disabilities may contact public officials in order to obtain public benefits or services instead of trying to improve the situation of their group in general.

${ }^{4}$ It would be important if we had conducted a multilevel analysis with random slopes at the country level. Yet as we mention in the following section our mixed effect specification allows only the intercept to vary between the 32 countries.
}

${ }^{5}$ Or the lack of such policies. We refer here to the absence of facilitation policies such as proxy voting, postal voting, etc.

${ }^{6}$ For a concise study regarding the development of the disability movement internationally the reader is advised to read Driedger's book (1989). 